\title{
RESEARCH
}

Open Access

\section{Single versus double chest drains after pulmonary lobectomy: a systematic review and meta-analysis}

\author{
Jinzhi You ${ }^{1 \dagger}$, Hailing Zhang ${ }^{2 \dagger}$, Wei $\mathrm{Li}^{1}$, Ninghuang Dai ${ }^{1}$ and Zhongfeng Zheng ${ }^{1 *}$
}

\begin{abstract}
Background: Previous randomized controlled trials have compared the efficacy and safety of single chest drain $(S C D)$ and double chest drains $(D C D)$ in the patients undergone pulmonary lobectomy, yet the results remain inconsistent. Therefore, we aimed to conduct this present systematic review and meta-analysis to evaluate the role of SCD and DCD in the patients undergone pulmonary lobectomy.

Methods: PubMed, Medline, EMBASE, Cochrane library, Web of Science, China National Knowledge Infrastructure, Wanfang, Weipu, and China Biomedical Literature databases were searched up to February 28, 2020, to identify the potential RCTs on SCD and DCD in the patients undergone pulmonary lobectomy. The main outcomes including verbal pain score, the duration of drainage (days), the length of hospital stay (days), and the incidence of air leak and re-drainage were collected and analyzed. All the data were processed and analyzed with software RevMan 5.3. We calculated and analyzed the odds ratios (OR) for dichotomous outcomes and the mean difference (MD) for continuous outcomes.
\end{abstract}

Results: A total of 11 RCTs with 1214 patients were included, in which 589 patients received SCD treatment and 625 patients $D C D$ treatment. The verbal pain score $(\mathrm{MD}=-0.54,95 \% \mathrm{Cl}(-0.87,-0.21))$, the duration of drainage $(\mathrm{MD}=-0.65,95 \% \mathrm{Cl}(-1.04,-0.26))$, and the length of hospital stay $(\mathrm{MD}=-0.55,95 \% \mathrm{Cl}(-0.80,-0.29))$ in $\mathrm{SCD}$ group were significantly less than that of DCD group. There were no significant differences on the incidence of air leak $(\mathrm{OR}=1.35,95 \% \mathrm{Cl}(0.86,2.11))$ and re-drainage $(\mathrm{OR}=0.88,95 \% \mathrm{Cl}(0.41,1.90))$ among the two groups.

Conclusions: SCD is a safe option, and it has the advantages of less postoperative pain, shortened duration of drain, and reduced length of hospital stay when compared with DCD in the patients undergone pulmonary lobectomy.

Keywords: Chest, Drain, Pulmonary lobectomy, Management, Treatment

\footnotetext{
*Correspondence: jpeoxo@163.com

${ }^{\dagger}$ Jinzhi You and Hailing Zhang contributed equally to this work.

'Department of Cardiothoracic Surgery, The Affiliated Suqian Hospital of

Xuzhou Medical University, No.138 South Huanghe Road, Sucheng District,

Sugian, China

Full list of author information is available at the end of the article
}

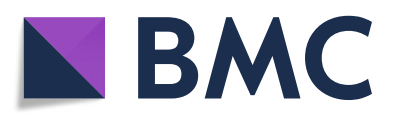

(- The Author(s). 2020 Open Access This article is licensed under a Creative Commons Attribution 4.0 International License, which permits use, sharing, adaptation, distribution and reproduction in any medium or format, as long as you give appropriate credit to the original author(s) and the source, provide a link to the Creative Commons licence, and indicate if changes were made. The images or other third party material in this article are included in the article's Creative Commons licence, unless indicated otherwise in a credit line to the material. If material is not included in the article's Creative Commons licence and your intended use is not permitted by statutory regulation or exceeds the permitted use, you will need to obtain permission directly from the copyright holder. To view a copy of this licence, visit http://creativecommons.org/licenses/by/4.0/. The Creative Commons Public Domain Dedication waiver (http://creativecommons.org/publicdomain/zero/1.0/) applies to the data made available in this article, unless otherwise stated in a credit line to the data. 


\section{Background}

Lung cancer is one of the most common malignant tumors with high mortality [1]. In recent years, the morbidity and mortality have increased sharply year by year, which seriously harms human health [2]. Surgery is the main treatment for lung cancer, and closed chest tubes are placed generally for drainage. The purpose of placing closed chest drains after lobectomy is mainly to drain the blood and gas from the chest cavity and prevent regurgitation, to restore the normal negative pressure in the chest cavity, thereby promoting the lung expansion and prevent infections in the chest cavity [3]. The closed drainage can be used to observe whether there is active bleeding in postoperative patients, which is conducive to the recovery of postoperative pulmonary function and reduces the incidence of pulmonary infection $[4,5]$. Therefore, the management of chest drains after pulmonary lobectomy is crucial to the prognosis of patients.

With the popularization of the concept of accelerated rehabilitation in recent years, more health care providers are endeavor to maximize the benefits of patients after surgery. There is currently controversy over the number of closed chest drainage tubes placed after surgery. The traditional chest drainage method after lobectomy is to place two drainage tubes. The main reason is that the double chest drains (DCD) can effectively drain the fluids, and it is safe and reliable to remove the tube either at the end of inspiration or at the end of expiration [6]. However, for single chest drain (SCD), it is necessary to quickly remove the tube after the end of inhalation to prevent the occurrence of pneumothorax [7]. It has also been reported that SCD can not only significantly reduce pain level after surgery but also can significantly reduce the drainages [8]. With the rise of the concept of rapid recovery, it is believed that DCD increases the pain and cost of patients, but whether the effect of SCD can achieve the effect of DCD remains to be further evaluated.

There are several randomized controlled trials (RCTs) [9-11] that have compared the role of SCD and DCD in the patients undergone pulmonary lobectomy, yet the results remain inconsistent. Several previous metaanalyses [8, 12-14] have focused on the effects and safety of SCD and DCD, but the sample size is rather small with lack of statistical testing power. Based on literature review, we have found that there are several recent related RCTs that have published. Therefore, it is necessary to conduct updated meta-analysis to identify the role of SCD and DCD in the patients undergone pulmonary lobectomy, thereby producing evidence for the management of pulmonary lobectomy.

The aim of this meta-analysis and systematic review was to evaluate the effects and safety of SCD and DCD in the patients undergone pulmonary lobectomy, to provide insights into the clinical management of pulmonary lobectomy.

\section{Methods}

This present study was established and reported in accordance with the recommendations and guidance of Preferred Reporting Items for Systematic Reviews and Meta-Analyses (PRISMA) [15].

\section{Literature research}

The literature researches were conducted in comply with the recommendations [16] of literature search in surgical systematic reviews. Two authors independently searched PubMed, Medline, EMBASE, Cochrane library, Web of Science, China National Knowledge Infrastructure (CNKI), Wanfang, Weipu, and China Biomedical Literature databases. The time range was set from the chest tube insertion to February 28, 2020. All RCTs comparing SCD and DCD in the patients undergone pulmonary lobectomy were identified and included. The search strategy was built as ("lobectomy" OR "chest" OR "thoracic") AND ("drain" OR "tube" OR "drainage" OR "single" OR "one" OR "double" OR "two") in every database. All relevant titles and abstracts were imported to the Endnote software for selection. In addition to the use of electronic searches, some conference papers and references were manually searched. Two authors conducted systematic evaluation of all identified articles based on inclusion and exclusion criteria.

\section{The inclusion and exclusion criteria}

The studies were included if they met every item of the following criteria: (1) RCT design; (2) patient underwent lobectomy without radiotherapy or chemotherapy before surgery, and it was the first time for the surgery in thoracic systems; (3) the study has compared the SCD and DCD; and (4) related outcomes such as the pain level after surgery, the duration of drains, etc. had reported, and the data can be extracted for data analysis. The studies were excluded if: (1) retrospective analysis, case report, reviews, etc. non-RCT design studies; (2) duplicate reports; and (3) patients undergone other surgeries concurrently.

\section{Data extraction}

Data extraction was performed independently by two authors. We developed a unified form to collect relevant data. We extracted the following information: first author, year of publication, type of study, the population of included participants, gender, age, type of surgery, and related reported outcomes including verbal pain score, the duration of drainage (days), the length of hospital stay (days), and the incidence of air leak and re-drainage. 
We discussed with the third author if there is a disagreement during the data extraction process.

\section{Risk of bias assessment}

The assessments of the quality of included RCTs were conducted with the bias risk assessment tools recommended by the Cochrane Collaboration [17]. The main contents included sequence generation, allocation concealment, blinding of participants and personnel, blinding of outcome assessment, incomplete outcome data, selective outcome reporting, and "other" issues. Each domain was defined as low, middle, and high risk of bias according to the criteria. The presence or absence of blinding of the study contributors-patients, surgeons, data collectors, outcome assessors, and data analystswas analyzed as previously suggested [18].

\section{Statistical analysis}

All the data were processed and analyzed with the software RevMan 5.3 recommended by the Cochrane library. We calculated and analyzed the odds ratios (OR) for dichotomous outcomes and the mean difference (MD) for continuous outcomes. The level of heterogeneity among the analyzed RCTs was evaluated with the $I^{2}$ statistics $\left(I^{2}>50 \%\right.$ indicating significant heterogeneity). And the fixed-effects model was applied if there was no statistically significant heterogeneity ( $\left.p \geq 0.10, I^{2}<50 \%\right)$; otherwise, randomeffects model was used $\left(p<0.10, I^{2}>50 \%\right)$. Sensitivity analysis was performed by removing one by one to see the changes of whole synthesized results. Besides, funnel plots and Begg's tests were applied to assess the publication bias. $p<0.05$ was considered as being statistically significant. For all the statistical analyses in this present meta-analysis, $p<$ 0.05 was considered as statistical significance, and all the detected tests were two-sided.

\section{Results}

\section{Study inclusion}

The process of study inclusion is presented in Fig. 1 . The first search resulted in 121 potentially relevant articles. After reviewing the titles and abstracts of the remaining 98 studies after duplicate exclusion, the full texts of 37 studies were retrieved. After further evaluation, 11 RCTs [9-11, 19-26] were included finally.

\section{The characteristic of included RCTs}

A total of 11 RCTs [9-11, 19-26] with 1214 patients with pulmonary lobectomy were included, specifically

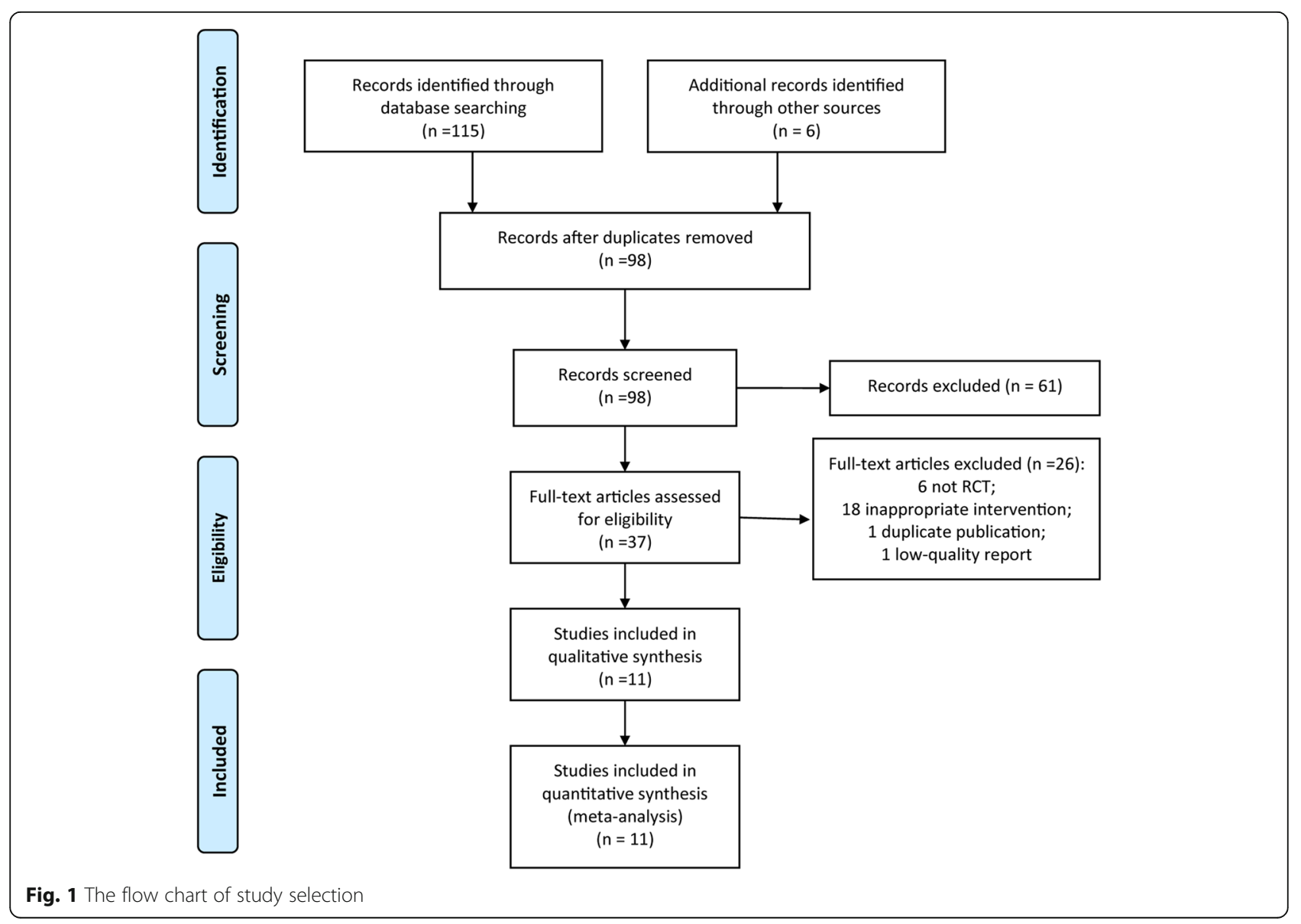


Table 1 The characteristics of included RCTs

\begin{tabular}{|c|c|c|c|c|c|c|c|c|c|}
\hline \multirow[t]{2}{*}{ Study } & \multirow[t]{2}{*}{ Country } & \multicolumn{2}{|c|}{$\begin{array}{l}\text { Sample } \\
\text { size }\end{array}$} & \multicolumn{2}{|c|}{$\begin{array}{l}\text { Gender (male/ } \\
\text { female) }\end{array}$} & \multicolumn{2}{|l|}{ Age } & \multirow[t]{2}{*}{ Follow-up period } & \multirow[t]{2}{*}{ The type of surgery } \\
\hline & & SCD & $\overline{D C D}$ & SCD & DCD & SCD & DCD & & \\
\hline Alex et al. [9] & UK & 60 & 60 & $48 / 12$ & $48 / 12$ & $65 \pm 8.4$ & $66 \pm 8.6$ & $\begin{array}{l}\text { Those patients with } \\
\text { chest drains were } \\
\text { assessed every hour } \\
\text { for the first } 24 \mathrm{~h} \text { and } \\
\text { then every } 6 \mathrm{~h} \text { until } \\
\text { removal. }\end{array}$ & Lobectomy \\
\hline Gomez-Caro et al. [10] & Spain & 60 & 59 & $9 / 51$ & $7 / 52$ & $65.5 \pm 9.4$ & $61.5 \pm 9.5$ & 30 days & $\begin{array}{l}\text { Upper and lower lobe } \\
\text { resection }\end{array}$ \\
\hline Han et al. [11] & China & 46 & 47 & $39 / 7$ & $32 / 15$ & $58.4 \pm 9.5$ & $58.2 \pm 9.0$ & Not available & Lobectomy \\
\hline Hu et al. [19] & China & 62 & 53 & $32 / 30$ & $27 / 26$ & 61.3 & 60.1 & Not available & $\begin{array}{l}\text { Left and right upper lobe } \\
\text { resection plus lymph node } \\
\text { dissection }\end{array}$ \\
\hline Li et al. [20] & China & 21 & 22 & $12 / 9$ & $13 / 9$ & $56.5 \pm 9.5$ & $57.2 \pm 9.0$ & Until discharge & Upper lobe resection \\
\hline Okur et al. [21] & Turkey & 50 & 50 & $37 / 13$ & $43 / 7$ & $54.74 \pm 14.34$ & $56.34 \pm 11.52$ & Until discharge & Lobectomy \\
\hline Pan et al. [22] & China & 48 & 48 & $26 / 22$ & $28 / 20$ & $56.37 \pm 6.28$ & $52.18 \pm 5.63$ & 30 days & Upper lobe resection \\
\hline Pawelczyk et al. [23] & Poland & 90 & 93 & $64 / 26$ & $54 / 39$ & $60.9 \pm 9.03$ & $60.7 \pm 8.906$ & Not available & $\begin{array}{l}\text { Upper and lower lobe } \\
\text { resection }\end{array}$ \\
\hline Tanaka et al. [24] & Japan & 54 & 54 & $38 / 16$ & $32 / 22$ & $66.8 \pm 7.5$ & $67.7 \pm 8.0$ & Not available & $\begin{array}{l}\text { Upper and lower lobe } \\
\text { resection }\end{array}$ \\
\hline Wang et al. [25] & China & 38 & 79 & $19 / 19$ & $45 / 34$ & $63.98 \pm 9.76$ & $65.77 \pm 8.58$ & Until discharge & Upper lobe resection \\
\hline Zhou and Yu [26] & China & 60 & 60 & $41 / 19$ & $39 / 21$ & $50.83 \pm 15.23$ & $52.55 \pm 13.23$ & Until discharge & Lobectomy \\
\hline
\end{tabular}

589 patients undergoing SCD treatment and 625 patients undergoing DCD treatment. The characteristics of included 11 RCTs were presented in Table 1 . The six included RCTs $[11,19,20,22,25,26]$ were conducted in China, one in the UK [9], Spain [10], Turkey [21], Poland [23], and Japan [24], respectively. The sample size ranged from 183 to 43 . And the pulmonary lobectomy varied from different part of lung tissue.

\section{The quality of included RCTs}

The quality of included RCTs was showed in Figs. 2 and 3. Although every included study mentioned randomization, only three studies [20, 22, 24] have reported the methods used for random number generation. One RCT [24] reported the blinded information regarding the group assignment and thoracentesis operation. None of the resting ten RCTs explicitly reported the distribution and concealment or any blind design among the method part. And no other significant biases were found.

\section{The meta-analysis of extracted outcomes The verbal pain score}

Seven included RCTs [9, 10, 21-25] reported the verbal pain score after pulmonary lobectomy. Significant

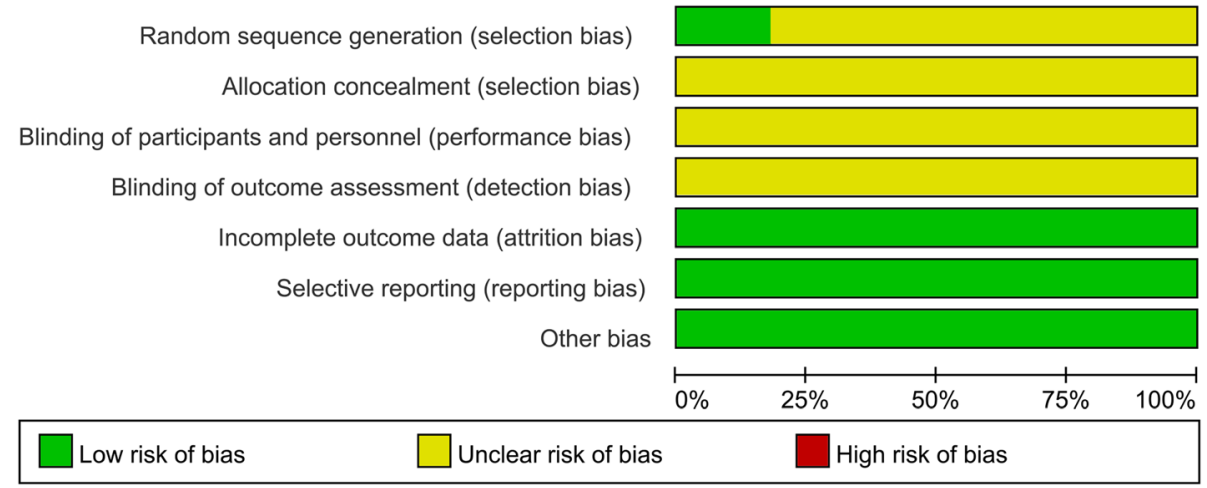

Fig. 2 Risk of bias graph 


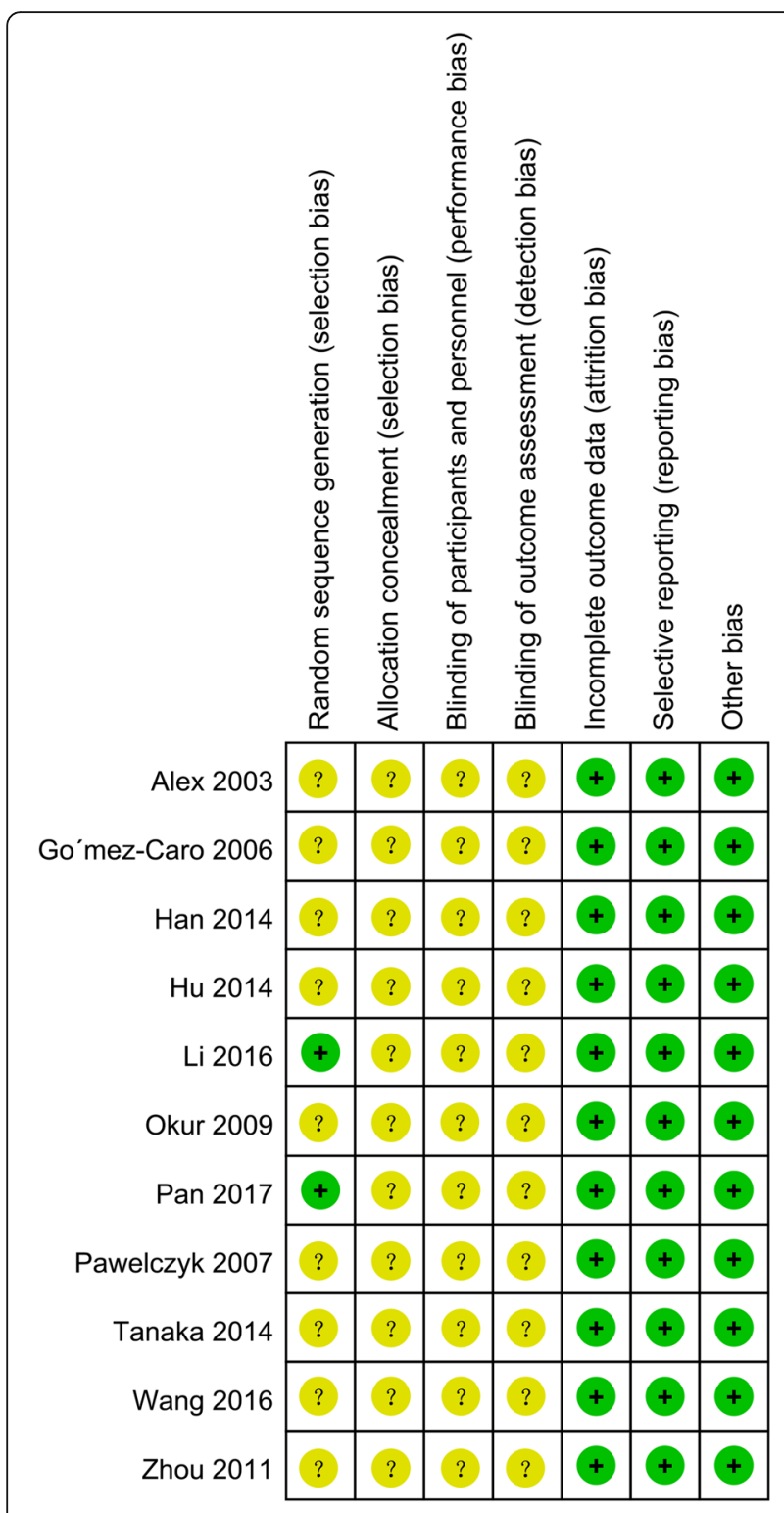

Fig. 3 Risk of bias summary

heterogeneity was found among included RCTs $\left(I^{2}=88 \%\right)$, and random model was applied. The analysis result showed that the verbal pain score in SCD group was significantly less than that of DCD treatment ( $M D=$ - 0.54, 95\%CI (- 0.87, - 0.21), Fig. 4a).

\section{The duration of drainage (days)}

All the included RCTs [9-11, 19-26] reported the duration of drainage (days) after pulmonary lobectomy. Significant heterogeneity was found among included RCTs $\left(I^{2}=79 \%\right)$, and random model was applied. The analysis result showed that the duration of drainage (days) in SCD group was significantly less than that of DCD treatment $(\mathrm{MD}=-0.65,95 \% \mathrm{CI}(-1.04,-0.26)$, Fig. $4 \mathrm{~b})$.

\section{The length of hospital stay (days)}

Nine included RCTs [9-11, 20-23, 25, 26] reported the length of hospital stay (days) after pulmonary lobectomy. No significant heterogeneity was found among included RCTs $\left(I^{2}=7 \%\right)$, and fix model was applied. The analysis result showed that length of hospital stay (days) in SCD group was significantly less than that of DCD treatment $(\mathrm{MD}=-0.55,95 \% \mathrm{CI}(-0.80,-0.29)$, Fig. 4c).

\section{The incidence of air leak}

Six included RCTs $[10,11,21-23,26]$ reported the incidence of air leak after pulmonary lobectomy. No significant heterogeneity was found among included RCTs $\left(I^{2}\right.$ $=0 \%$ ), and fix model was applied. The analysis result showed that there was no significant difference on the incidence of air leak in SCD and DCD group (OR = $1.35,95 \% \mathrm{CI}(0.86,2.11)$, Fig. 4d).

\section{The incidence of re-drainage}

Four included RCTs [10, 11, 21, 23] reported the incidence of re-drainage after pulmonary lobectomy. No significant heterogeneity was found among included RCTs $\left(I^{2}=0 \%\right)$, and fix model was applied. The analysis result showed that there was no significant difference on the incidence of re-drainage in SCD and DCD group (OR = $0.88,95 \% \mathrm{CI}(0.41,1.90)$, Fig. $4 \mathrm{e})$.

\section{Sensitivity analysis}

The sensitivity analyses were conducted by excluding single RCT one by one and excluded the studies from the same countries; the results of sensitivity analysis of all outcomes had showed no significant result changes among the overall estimates.

\section{Publication bias}

The publication bias was assessed with funnel plot in this present study. The funnel plots (Fig. 5) for all synthesized outcomes remained symmetrical, indicating no visual signs of publication bias among the included studies.

\section{Discussion}

The application of thoracic drainage after lobectomy has been in the clinic for many years. By placing a closed chest drainage tube, it can achieve the effects of draining gas and fluids from the chest cavity, promoting lung expansion, preventing chest infections, and rebuilding negative pressure $[27,28]$. Meanwhile, by observing the amount, characteristics of drainages, and the fluctuation of the water column, some abnormal conditions can be found and treated in time [29]. At present, it is common that SCD is placed after lobectomy of upper lung tissue in China, while DCD are placed after lobectomy of lower lung tissue [14]. The potential reason is that the closure 


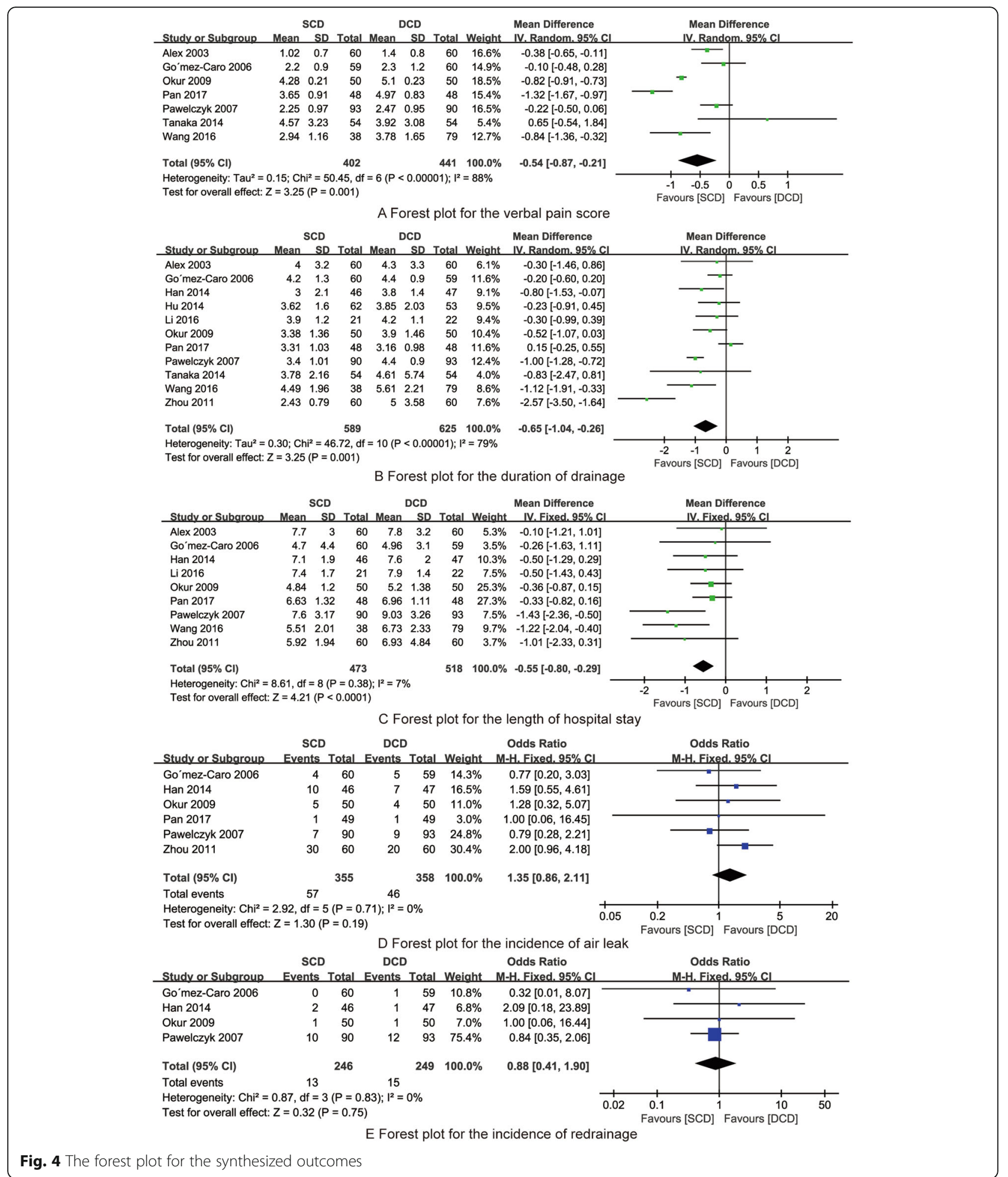

of the residual cavity after lobectomy depends on adequate drainage with aims to promote lung expansion and avoid mediastinum displacement [30]. The length of the drain inserted into the chest cavity is easily restricted [31]. If it is placed too high, the pleural fluid located below it cannot be easily drained. However, placing it too low can be folded up by the pressure of the diaphragm to bend and affect the drainage output [32]. Sometimes it can also stimulate the diaphragm to cause stubborn hiccups or severe pain during breathing, 

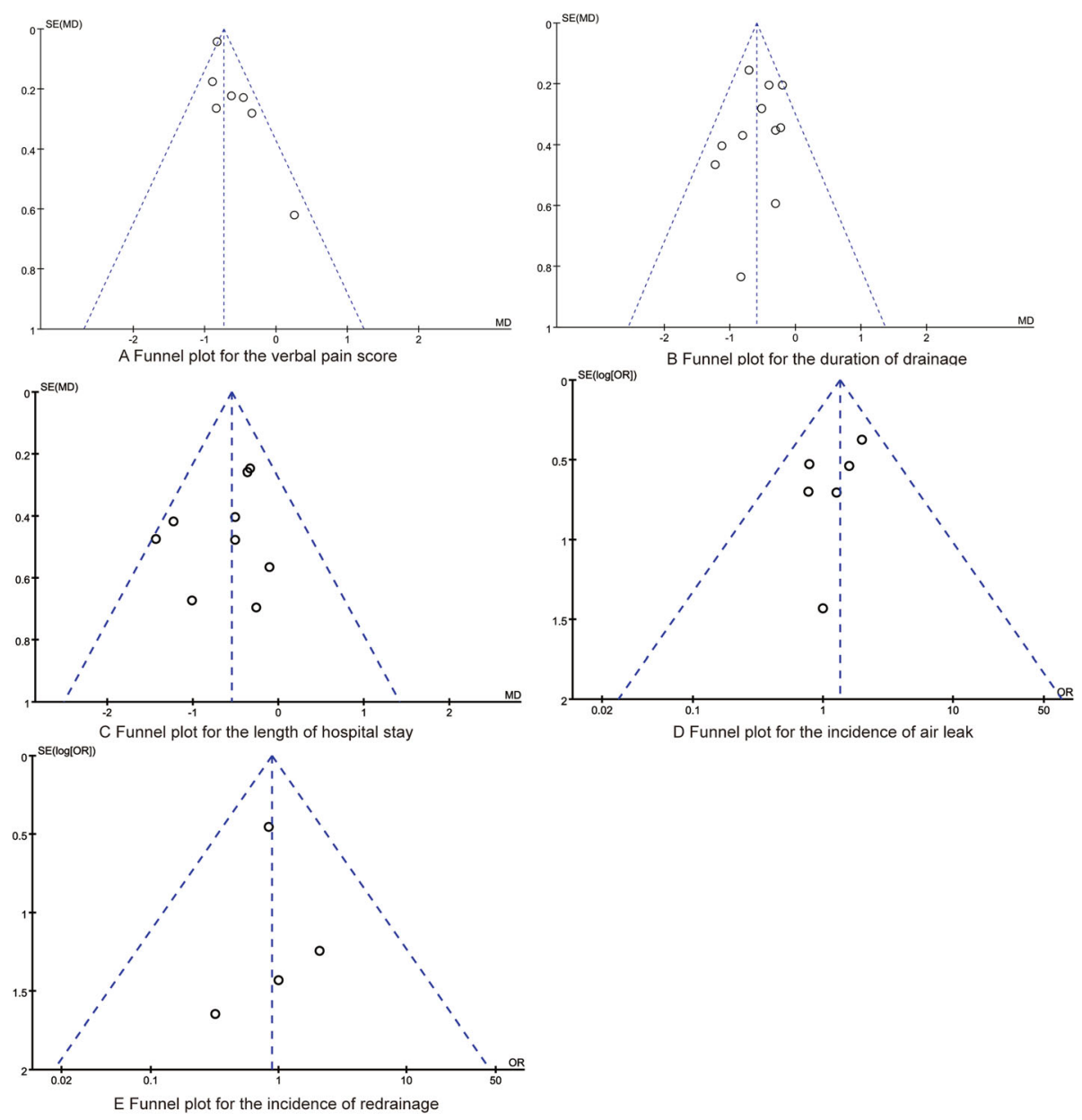

Fig. 5 The funnel plots for synthesized outcomes

resulting in limited breathing [33]. We have conducted a meta-analysis of included RCTs comparing the effects and safety of SCD and DCD after pulmonary lobectomy, and we have found that the pain level in SCD is much less than that of $\mathrm{DCD}$, and the duration of drainage and hospital stay are much shorter than DCD, and SCD and DCD do not act different role in the incidence of air leak and re-drainage. Therefore, SCD may be more advantageous in the management of patients undergone pulmonary lobectomy.

There are also reports that SCD can not only significantly reduce the pain but also can significantly reduce drainage, which is beneficial for patients to go to the ground early and exercise early to promote the recovery of respiratory function [34, 35]. Previous studies [13, 36, 37] have indicated that the effect of SCD is better than or equivalent to traditional DCD drainage, and it does not increase the incidence of complications and mortality. Furthermore, the clinical advantages of SCD also include that it is conducive to skin incision healing [38]. It is noteworthy that SCD is generally placed at the top of the chest, even though related studies [39, 40] have shown that the main advantages of SCD after lobectomy have nothing to do with surgical approaches; there are few reports on SCD placement in the epilobectomy; future studies on this type of surgery are needed.

The drainage volume of the SCD is less than that of DCD; there are few possible reasons for the decrease of drainages in SCD. Firstly, the duration of the SCD is much shorter than that of DCD; the increased pleural secretion in DCD can be explained by more pleural fluid secretion from the pleura with regard to more irritation of DCD [41]. Secondly, more advanced instruments and materials are used in lung resection nowadays, such as linear staplers for incomplete fissures, sealing materials for substantial air leaks, or other advanced materials for hemostasis. All of those advancements promote the use of SCD and ensure the effects and safety of SCD.

This present meta-analysis has certain limitations that should be considered. Firstly, the quality of the included literature varies, and the analysis found that several outcomes have significant heterogeneity; the potential 
source of bias cannot be analyzed due to limited data. Secondly, the type of the drains and the methods of the pulmonary lobectomy among the included RCTs are different; the meta-analysis result may be influenced. Thirdly, our review is limited by the methodological quality of included RCTs; some information related to quality assessment is insufficient to make defined and solid judgment. Blinding reduces performance and detection bias in RCTs. There is evidence that lack of blinding leads to overestimation of treatment effects in trials [18]. Since surgical trials use interventions with a physical component, blinding is often complicated. Therefore, future studies with rigorous design and appropriate reporting format are warranted.

\section{Conclusions}

In conclusion, the results of this present meta-analysis have found that SCD is much better than DCD in reducing the postoperative pain level, shortening the duration of drains, and decreasing the length of hospital stay. At the moment, there is just no convincing evidence that more than one drainage has any benefit. Therefore, SCD is a better option for patients undergone pulmonary lobectomy. However, we have not found any differences in the related complications such as the incidence of air leak and re-drainage between SCD and DCD, which may be associated with insufficient sample size. Therefore, large-sample and multicenter RCTs on the role of SCD and DCD are highlighted in the future.

\section{Abbreviations}

SCD: Single chest drain; DCD: Double chest drains; RCTs: Randomized controlled trials; PRISMA: Preferred Reporting Items for Systematic Reviews and Meta-Analyses; CNKI: China National Knowledge Infrastructure; OR: Odds ratios; MD: Mean difference

\section{Acknowledgements}

None.

\section{Authors' contributions \\ $J Y$ and $Z Z$ designed the research; J $Y, H Z$, and $W L$ searched the literature and extracted the data; J Y, HZ, and N D analyzed the data; J Y wrote the first draft of the manuscript; $Z Z$ had primary responsibility for the final content. All authors read and approved the final manuscript.}

\section{Funding}

None

\section{Availability of data and materials}

All data generated or analyzed during this study are included in this published article.

\section{Ethics approval and consent to participate}

Not applicable.

\section{Consent for publication}

Not applicable.

\section{Competing interests}

The authors declare that they have no competing interests.

\section{Author details}

'Department of Cardiothoracic Surgery, The Affiliated Suqian Hospital of Xuzhou Medical University, No.138 South Huanghe Road, Sucheng District, Suqian, China. ${ }^{2}$ The Suqian Clinical College of Xuzhou Medical University, Suqian, China

Received: 28 April 2020 Accepted: 3 July 2020

Published online: 20 July 2020

\section{References}

1. Cao M, Chen W. Epidemiology of lung cancer in China. Thorac Cancer. 2019;10(1):3-7.

2. Nasim F, Sabath BF, Eapen GA. Lung cancer. Med Clin North Am. 2019; 103(3):463-73

3. Miller DL, Helms GA, Mayfield WR. Digital drainage system reduces hospitalization after video-assisted thoracoscopic surgery lung resection. Ann Thorac Surg. 2016;102(3):955-61.

4. Pompili C, Salati M, Brunelli A. Chest tube management after surgery for pneumothorax. Thorac Surg Clin. 2017;27(1):25-8.

5. Yang $Z, H u T$, Shen $H$, Huang $H$. Application of small-bore pigtail catheter to improve pleural drainage after single-incision thoracoscopic lobectomy for lung cancer. ANZ J Surg. 2020;90(1-2):139-43.

6. Koryllos A, Eggeling S, Schega O, Schweigert M, Leschber G. Delphi expert consensus of the German thoracic surgery society on the management of chest tube drainage. Zentralbl Chir. 2020;145(1):99-107.

7. Zhang JT, Dong S, Chu XP, Lin SM, Yu RY, Jiang BY, et al. Randomized trial of an improved drainage strategy versus routine chest tube after lung wedge resection. Ann Thorac Surg. 2020;109(4):1040-6.

8. Liu X, Zhao F, Dai J, Zhou D, Chen W. Comparison of the single or double chest tube applications after lobectomy: a systematic review and metaanalysis. Chin J Clin Thorac Cardiovasc Surg. 2019;26(6):583-9.

9. Alex J, Ansari J, Bahalkar P, Agarwala S, Rehman MU, Saleh A, et al. Comparison of the immediate postoperative outcome of using the conventional two drains versus a single drain after lobectomy. Ann Thorac Surg. 2003;76(4):1046-9.

10. Gomez-Caro A, Roca MJ, Torres J, Cascales P, Terol E, Castaner J, et al. Successful use of a single chest drain postlobectomy instead of two classical drains: a randomized study. Eur J Cardiothorac Surg. 2006;29(4):562-6.

11. Han Z, Song Z, Su J, Liu L, Che G. Application of single thoracic drainage tube for rapid rehabilitation after lung cancer surgery. Chin J Clin Thorac Cardiovasc Surg. 2014;21(1):7-10.

12. $\mathrm{Xu} \mathrm{L}, \mathrm{Li} Y, \mathrm{Hu}$ K. Meta-analysis of the clinical efficacy of two drainage methods in the treatment of tuberculous pleurisy. J Med Res. 2017;46(1): $115-9$.

13. Zhang X, Lv D, Li M, Sun G, Liu C. The single chest tube versus double chest tube application after pulmonary lobectomy: a systematic review and meta-analysis. J Cancer Res Ther. 2016;12(Supplement):C309-16.

14. Zhou D, Deng XF, Liu QX, Chen Q, Min JX, Dai JG. Single chest tube drainage is superior to double chest tube drainage after lobectomy: a metaanalysis. J Cardiothorac Surg. 2016;11(1):88.

15. Moher D, Liberati A, Tetzlaff J, Altman DG, Group P. Preferred reporting items for systematic reviews and meta-analyses: the PRISMA statement. PLoS Med. 2009;6(7):e1000097.

16. Goossen K, Tenckhoff S, Probst P, Grummich K, Mihaljevic AL, Buchler MW, et al. Optimal literature search for systematic reviews in surgery. Langenbeck's Arch Surg. 2018;403(1):119-29.

17. Higgins JP, Altman DG, Gotzsche PC, Juni P, Moher D, Oxman AD, et al. The Cochrane Collaboration's tool for assessing risk of bias in randomised trials. BMJ. 2011;343:d5928.

18. Probst P, Zaschke S, Heger P, Harnoss JC, Huttner FJ, Mihaljevic AL, et al. Evidence-based recommendations for blinding in surgical trials. Langenbeck's Arch Surg. 2019;404(3):273-84.

19. Hu B, Zhou Z, Yuan Y, Wang Z. Application of improved single thoracic drainage tube drainage after radical mastectomy of upper lobe lung cancer. J Xuzhou Med Coll. 2014;34(12):900-2.

20. Li X, Zhang L, Zhong N. Application of single thoracic drainage tube after lung cancer resection. J Clin Pulmon Med. 2016;21(12):2173-7.

21. Okur E, Baysungur V, Tezel C, Sevilgen G, Ergene G, Gokce M, et al. Comparison of the single or double chest tube applications after 
pulmonary lobectomies. Eur J Cardiothorac Surg. 2009;35(1):32-5 discussion 35-36.

22. Pan $Y$, Shao F, Kong L. Application of single chest drainage in minimally invasive surgery for patients with non-small cell lung cancer. Chin Clin Res. 2017;30(9):1231-3.

23. Pawelczyk K, Marciniak M, Kacprzak G, Kolodziej J. One or two drains after lobectomy? A comparison of both methods in the immediate postoperative period. Thorac Cardiovasc Surg. 2007;55(5):313-6.

24. Tanaka M, Sagawa M, Usuda K, Machida Y, Ueno M, Motono N, et al. Postoperative drainage with one chest tube is appropriate for pulmonary lobectomy: a randomized trial. Tohoku J Exp Med. 2014;232(1):55-61.

25. Wang Y, Xia H, Huang H, Chen S, He J, Ma H. Efficacy analysis of single tube drainage after total thoracoscopic upper lobectomy. Zhejiang Clin Med. 2016;18(12):2254-5.

26. Zhou H, Yu N. Comparison of the effects of two closed chest drainage methods after lobectomy. Chin J Mod Nurs. 2011;17(32):3881-2.

27. Nakanishi R, Fujino Y, Kato M, Miura T, Yasuda M, Oda R, et al. Early chest tube removal after thoracoscopic lobectomy with the aid of an additional thin tube: a prospective multi-institutional study. Gen Thorac Cardiovasc Surg. 2018;66(12):723-30.

28. Jiang H, Wang J, Yuan DF, Fang JW, Li Z. Feasibility and safety of early chest tube removal after complete video-assisted thoracic lobectomy. Indian $J$ Cancer. 2015;51(Suppl 2):e60-2.

29. Takamochi K, Nojiri S, Oh S, Matsunaga T, Imashimizu K, Fukui M, et al. Comparison of digital and traditional thoracic drainage systems for postoperative chest tube management after pulmonary resection: a prospective randomized trial. J Thorac Cardiovasc Surg. 2018;155(4):1834-40.

30. Mayor JM, Lazarus DR, Casal RF, Omer S, Preventza O, Simpson K, et al. Air leak management program with digital drainage reduces length of stay after lobectomy. Ann Thorac Surg. 2018;106(6):1647-53.

31. Kim SS, Khalpey Z, Daugherty SL, Torabi M, Little AG. Factors in the selection and management of chest tubes after pulmonary lobectomy: results of a national survey of thoracic surgeons. Ann Thorac Surg. 2016; 101(3):1082-8.

32. Filosso PL, Guerrera F, Lausi PO, Ruffini E. How should we manage the chest drainage after a video-assisted thoracoscopic surgery lobectomy? J Thorac Dis. 2019;11(6):2212-4.

33. Jacobsen K, Talbert S, Boyer JH. The benefits of digital drainage system versus traditional drainage system after robotic-assisted pulmonary lobectomy. J Thorac Dis. 2019;11(12):5328-35.

34. Zhang TX, Zhang Y, Liu ZD, Zhou SJ, Xu SF. The volume threshold of 300 versus $100 \mathrm{ml} /$ day for chest tube removal after pulmonary lobectomy: a meta-analysis. Interact Cardiovasc Thorac Surg. 2018;27(5):695-702.

35. Lai Y, Wang X, Zhou H, Kunzhou PL, Che G. Is it safe and practical to use a Foley catheter as a chest tube for lung cancer patients after lobectomy? A prospective cohort study with 441 cases. Int I Surg. 2018;56:215-20.

36. Lijkendijk M, Neckelmann K, Licht PB. External suction and fluid output in chest drains after lobectomy: a randomized clinical trial. Ann Thorac Surg. 2018;105(2):393-8.

37. Brunelli A, Cassivi SD, Fibla J, Di Nunzio L. Pleural pressure immediately after pulmonary lobectomy: single versus double chest tubes for suction. J Thorac Cardiovasc Surg. 2010;140(3)::52-3.

38. Nagahiro I, Miyamoto M, Sugiyama H, Nouso H, Kawai T, Toda K, Matsumoto $Y$, et al. Bronchial injury due to double-lumen endobronchial tube. Kyobu Geka. 2011;64(5):375-8.

39. Tang $S, W u$ Q, Shu Y. Status and progress of closed chest drainage management after lung cancer surgery. Chin J Thorac Surg. 2019;6(3):182-6.

40. Yang H, Wang L, Zhou T, Zhu J. Clinical study on the use of disposable gastric tubes for closed chest drainage after lobectomy. West China Med J. 2015;33(5):140-2.

41. Wu D, Li Y, Dai C: Observation and nursing characteristics of closed chest drainage for patients with lung cancer complicated with liver cirrhosis Journal of Practical Cardio-Cerebro-Pulmonary Vascular Disease. 2012;20(7): $1225-6$.

\section{Publisher's Note}

Springer Nature remains neutral with regard to jurisdictional claims in published maps and institutional affiliations.

Ready to submit your research? Choose BMC and benefit from:

- fast, convenient online submission

- thorough peer review by experienced researchers in your field

- rapid publication on acceptance

- support for research data, including large and complex data types

- gold Open Access which fosters wider collaboration and increased citations

- maximum visibility for your research: over $100 \mathrm{M}$ website views per year

At BMC, research is always in progress.

Learn more biomedcentral.com/submissions 